\title{
The impact of induction generator and PWM Inverter with energy storage on weak grids
}

\author{
H. Bludszuweit, J.A. Domínguez and M. García \\ Department of Electrical Engineering \\ University of Zaragoza \\ C / María de Luna 3, 50018 Zaragoza (Spain) \\ phone:+34 97676 2404, fax: + 3497676 2226, e-mail: hblud@unizar.es, jadona@unizar.es,mggracia@unizar.es
}

\begin{abstract}
The impact of wind energy generation connected to a weak grid is studied with SIMULINK ${ }^{\circledR}$ as simulation platform. The wind energy conversion system is modelled by a squirrel cage asynchronous induction machine (ASM). The grid is modelled as an infinite bus. In the proposed system the ASM is connected to the grid through a DC-link with incorporated battery storage. An ultracapacitor (UCap) bank in parallel to the battery reduces the current ripple which is originated by the PWM - IGBT bridges and absorbs rapid power peaks. Different degrees of grid strength for 2 disturbing events (A: 3-phase fault and B: Voltage dip) are studied. The simulation model permits a sizing of the storage system according to the desired stabilizing capabilities of the system.
\end{abstract}

From the simulation results can be concluded that under weak grid conditions the DC-link need to have a voltage control to ensure the stability of the system. Special attention must be paid to the power quality at the inverter output of the DC-link if renewable generation exceeds 5 $\%$ of the short circuit power at the coupling point.

The simulated ASM generator is rated at $75 \mathrm{~kW} / 400 \mathrm{~V}$. The DC-link operates at $700 \mathrm{~V}$ nominal voltage, the battery is rated at $340 \mathrm{kWh}(\mathrm{C}=500 \mathrm{Ah}), 34 \mathrm{~kW}$ at discharge rate $\mathrm{C} 0.1$ and $170 \mathrm{~kW}$ at discharge rate $\mathrm{C} 0.5$ with a UCap of $0.5 \mathrm{~F}$ in parallel, rated at $600 \mathrm{~A}$ discharge current.

Key words: weak grid stability, distributed generation, storage, PWM-inverter

\section{Nomenclature}

$\begin{array}{ll}\text { Abbreviations: } \\ \text { ASM } & \text { Asynchronous machine } \\ \text { EPS } & \text { Electrical power system } \\ \text { ESS } & \text { Energy storage system } \\ \text { IGBT } & \text { Insulated gate bipolar transistor } \\ \text { PCC } & \text { Point of common coupling } \\ \text { PF } & \text { Power factor } \\ \text { PWM } & \text { Pulse width modulation } \\ \text { REE } & \text { Red Eléctrica Española } \\ \text { RPL } & \text { Renewable penetration level } \\ \text { SCR } & \text { Short circuit ratio } \\ \text { THD } & \text { Total harmonic distortion } \\ \text { UCap } & \text { Ultracapacitor } \\ \text { WECS } & \text { Wind energy conversion system }\end{array}$

Symbols:

$\begin{array}{ll}L_{l s} & \text { Stator leakage inductance [H] , [p.u.] } \\ L_{r s} & \text { Rotor leakage inductance [H] , [p.u.] } \\ R_{S} & \text { Stator resistance [ } \Omega \text { ] , [p.u.] } \\ R_{r} & \text { Rotor resistance [ } \Omega \text { ] , [p.u.] } \\ H & \text { Inertia constant [s] } \\ H_{A S M} & \text { Inertia constant ASM generator [s] } \\ H_{W T} & \text { Inertia constant Wind turbine [s] } \\ S_{A S M} & \text { Nominal power of the ASM generator [VA] } \\ S_{D C} & \text { Nominal power of the DC-Converter [VA] } \\ S_{S C} & \text { Short circuit power of the grid (EPS) [VA] } \\ V_{a c} & \text { Voltage of the ac-system (grid-side) [V], [p.u.] } \\ V_{A S M} & \text { Voltage of the ASM generator [V] , [p.u.] } \\ V_{R M S} & \text { Voltage root mean square [V] , [p.u.] } \\ X / R \text { or } & \text { Damping factor of the grid impedance } \\ \tan \varphi & \\ Z_{t h}, Z_{t h} & \text { Grid Thevenin impedance [ } \Omega \text { ], [p.u.] }\end{array}$




\section{Introduction}

The fluctuations of power supply by renewable energies lead to the conclusion that energy storage has to be integrated as soon as its penetration level exceeds certain limits. Energy storage can improve the stability of the electrical power system (EPS) providing the necessary power or "spinning" reserve needed to counteract stability problems. According to Slootweg [1] these problems can be classified as transient stability (short circuits, voltage drops) and small signal stability (generation oscillations). In this work only transient stability is observed.

Slootweg discusses in [1] the impact of different types of wind energy conversion systems (WECS) on both, transient and small signal stability. As the most critical WECS type he identifies the constant speed generators with squirrel cage induction machines because variable speed wind turbines have the capacity of kinetic energy storage and reactive power control. The latter enables variable speed wind turbines to operate in voltage control mode. The benign influence of an active participation of distributed generation in voltage control is stressed in this occasion. Best results are obtained by a DC-connection of a wind park to the grid. This leads to the approach of this work. The DC-link with energy storage offers a wide range of control possibilities. On the one hand the fluctuations of the renewable generation can be absorbed and only the desired amount of energy is injected to the distribution system. On the other hand the DC-link can improve system stability by injecting or absorbing active and reactive power. The only limitation is given by the power rating of the converters. Combined with an intelligent measurement strategy, this configuration might be able to reinforce weak grids by means of renewable energy generation. In the literature very little examples can be found about this issue but some promising studies have been done for island grids in Greece [3], Portugal [4] and the Canary Islands [5].

The transient stability analysis strategy in this study is similar to the method presented in [1]. The parameters for the energy storage system (battery and the ultracapacitor model) are obtained by a simulated system presented in [2]. There, a lead acid battery was modelled in SIMULINK $^{\circledR}$ in a continuous state space which was connected to a DC bus. To reduce the battery current ripple Ultracapacitors were connected in parallel. For the dynamic simulations presented here, the battery is simulated as a passive RC-network with a constant DCvoltage source. The parameters (voltage and RCcomponents) are extracted from the model in [2] and assumed to be constant.

One of the events that cause most severe stability problems are voltage dips. For conventional generation in relatively strong grids this is not a mayor problem but with the increasing penetration levels of wind energy generation this type of perturbation has become very important. A few years ago, wind farms were obligated to disconnect from the grid when the voltage fell below a certain limit. Now, new wind generators need to be able to "ride trough" a voltage dip. The legislation for Spain is not yet concluded but in a draft version [7] a standard voltage dip is defined.

The simulation model permits a sizing of the storage system according to the desired stabilizing capabilities of the system. For short disturbances such as short circuits or voltage dips only ultra capacitors may be enough but to smooth the energy output considerably, batteries are needed. The battery size used in the presented results is good to guarantee 10 minute constant power output if a simple prediction method is applied (see [2]).

\section{Description of the system}

\section{A. Definition of the grid strength}

Kundur [3] defines an ac system as "weak" if it has (a) high impedance and/or (b) low mechanical inertia. In this work only the aspect of high impedance is considered hence the ac system is modelled as an infinite bus with infinite inertia. In [3] for HVDC connections a short circuit ratio SCR is defined as follows:

$$
S C R=\frac{S_{S C}}{S_{D C}}
$$

where

$S C R$ : Short circuit ratio of the grid

$S_{S C}$ : Short-circuit MVA of the ac system (grid)

$S_{D C}:$ DC converter MW rating

Kundur gives a traditional classification where the ac system strength is:

- High, if SCR is greater than 5

- Moderate if SCR is between 3 and 5

- Low, if SCR is less than 3

If better control algorithms are applied, a SCR of 4 is considered as high strength. In this work SCR values between 2 and 10 are considered. Based on the definition of SCR a renewable penetration level (RPL) can be defined as basically an inverse SCR:

$$
R P L=100 \% \cdot \frac{S_{\mathrm{ASM}}}{S_{\mathrm{SC}}}
$$

where

$R P L$ : Renewable penetration level

$S_{A S M}$ : Nominal power of the induction generator

$S_{S C}:$ Short circuit power of the EPS (grid)

In the simulation, the ASM generator stands for the renewable power generation (e.g. constant speed WECS) and is equivalent to the dc converter rating in the definition of SCR.

The Thevenin equivalent impedance of the ac grid is defined as:

$$
Z_{t h}=\frac{V_{a c}^{2}}{S_{S C}}
$$


where

$Z_{t h} \quad:$ Thevenin equivalent impedance of the ac grid

$V_{a c}:$ Nominal line to line voltage

$S_{S C}:$ Short circuit power of the EPS (grid)

If the rated power of the ASM generator is defined as the system base power, the per unit Thevenin impedance of the ac system can be written as:

$$
\mathrm{z}_{t h}=\frac{V_{a c}^{2}}{S_{S C}} \cdot \frac{S_{A S M}}{V_{A S M}^{2}}
$$

where

$Z_{t h} \quad:$ per unit Thevenin impedance of the ac system

$V_{A S M}:$ Nominal line to line voltage of the ASM

$S_{A S M}$ : Nominal power of the ASM

If the voltage levels of the generator and the grid are the same as in the case of direct coupling without transformer, $V_{a c}$ is equal to $V_{A S M}$ and the Thevenin impedance of the grid in p.u. is equal to the renewable penetration level RPL.

According to [3] the phase angle of the Thevenin equivalent impedance $Z_{\text {th }}$ has an impact on the system control stability. This angle can be termed as "damping angle" and its value is in the range of $75^{\circ}$ to $85^{\circ}$ for transmission lines. The term "damping angle" refers to the damping effect of the resistive component of $Z_{t h}$. The tangent of this angle is the often used $\mathrm{X} / \mathrm{R}$ ratio. Here the relation between the resistive and the inductive component of the impedance is given directly. Distribution networks tend to have lower $\mathrm{X} / \mathrm{R}$ ratios than transmission systems. Local resistive loads for example contribute to the damping of the system and improve its control stability inductive loads have the opposite effect.

\section{B. Reference system}

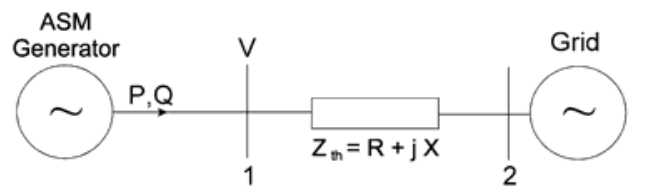

Fig. 1. Reference system configuration

In the reference system, the ASM generator is directly connected through an impedance to an infinite bus as in figure 1. The ASM is simulated in SIMULINK ${ }^{\circledR}$ as a squirrel cage induction generator (p.u. type). Its nominal values are set to $75 \mathrm{~kW} / 400 \mathrm{~V} / 50 \mathrm{~Hz}$. The machine parameters are taken from [1] and the inertia constant is set to the sum of generator and wind turbine inertia (see table I). This means a simplification of the model used in [1] where a two mass model is proposed. It is intended to include in the simulation a two mass model in the near future.

According to the assumptions in [1] the X/R-ratio is set constant to 10 . In the stability analysis the penetration level RPL (i.e. grid impedance $z_{t h}$ ) while the generation power is always kept constant. The weak grid is modelled in SIMULINK ${ }^{\circledR}$ as a simplified synchronous machine (SSM) with infinite inertia. Having an ASM with $75 \mathrm{~kW}$ rated power, a $S_{S C}$ of $750 \mathrm{~kW}$ for example would mean a $Z_{\text {th }}$ of 0.1 or a RPL of $10 \%$.

TABLE I. - ASM Parameters according to Slootweg [1].

\begin{tabular}{ll}
\hline Generator Characteristic & Value \\
\hline Number of poles & 4 \\
Generator nominal speed & $1517 \mathrm{rpm}$ \\
Mutual Inductance $L_{m}$ & $3.0 \mathrm{p.u}$. \\
Stator leakage inductance $L_{s} \sigma$ & $0.010 \mathrm{p} . \mathrm{u}$. \\
Rotor leakage inductance $L_{r} \sigma$ & $0.008 \mathrm{p} . \mathrm{u}$. \\
$\begin{array}{l}\text { Stator resistance } R_{S} \\
\text { Rotor resistance } R_{r}\end{array}$ & $0.01 \mathrm{p} . \mathrm{u}$. \\
$\begin{array}{l}\text { Compensating capacitor } \\
\text { (only in the reference case) }\end{array}$ & $0.01 \mathrm{p} . \mathrm{u}$. \\
Total Inertia constant $H$ & $0.5 \mathrm{p.u}$. \\
$\quad \begin{array}{l}\text { ASM generator } H_{A S M} \\
\quad \text { Wind turbine } H_{W T}\end{array}$ & $3.0 \mathrm{~s}$ \\
\hline
\end{tabular}

\section{DC-Link with energy storage}

In this configuration, a $700 \mathrm{~V}$ DC-link is introduced between the ASM and the distribution grid (see Fig. 2).

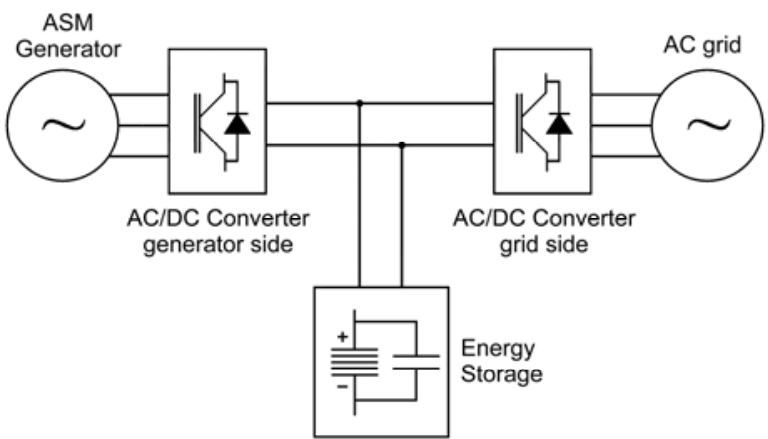

Fig. 2. Configuration with DC-Link and energy storage

The main issues of the DC link are: (a) its bi-directional PWM-IGBT architecture (back to back) and (b) the incorporation of a lead acid battery pack with an ultracapacitor bank in parallel (see TABLE II). The IGBT-bridges are modelled with the universal bridge model predefined in SIMULINK ${ }^{\circledR}$ (SimPowerSystems). The battery and the ultracapacitor are modelled with simple RC-networks.

The DC-link is designed as a back to back converter. At the generator side the control has to limit the current at generator starting (smooth starting) and provide the reactive power needed by the generator. In addition the rotor speed can be controlled.

At the grid side, several tasks have to be solved by the inverter control. At first the operation under normal conditions must be assured which means power factor and power flow control. During disturbances like voltage 
drops or short circuits, the grid-connected converter must react properly to protect itself and eventually disconnect the DC-link from the grid. In case of voltage drops it can contribute to stabilize the voltage by the injection of reactive power (voltage control mode).

TABLE II. - Parameters of the main system components.

\begin{tabular}{lccc}
\hline System Component & $\begin{array}{c}\text { Voltage } \\
{[\mathbf{V}]}\end{array}$ & $\begin{array}{c}\text { Power } \\
{[\mathbf{k W}]}\end{array}$ & other \\
\hline $\begin{array}{l}\text { ASM Generator } \\
\text { Back to Back }\end{array}$ & 400 & 75 & $50 \mathrm{~Hz}$ \\
converter & 700 & 75 & \\
Lead Acid Battery & 700 & 170 & $340 \mathrm{kWh}$ \\
Ultracapacitor & 700 & 420 & $600 \mathrm{~A}$ \\
Grid connection & 400 & $150-1500$ & $50 \mathrm{~Hz}$ \\
\hline
\end{tabular}
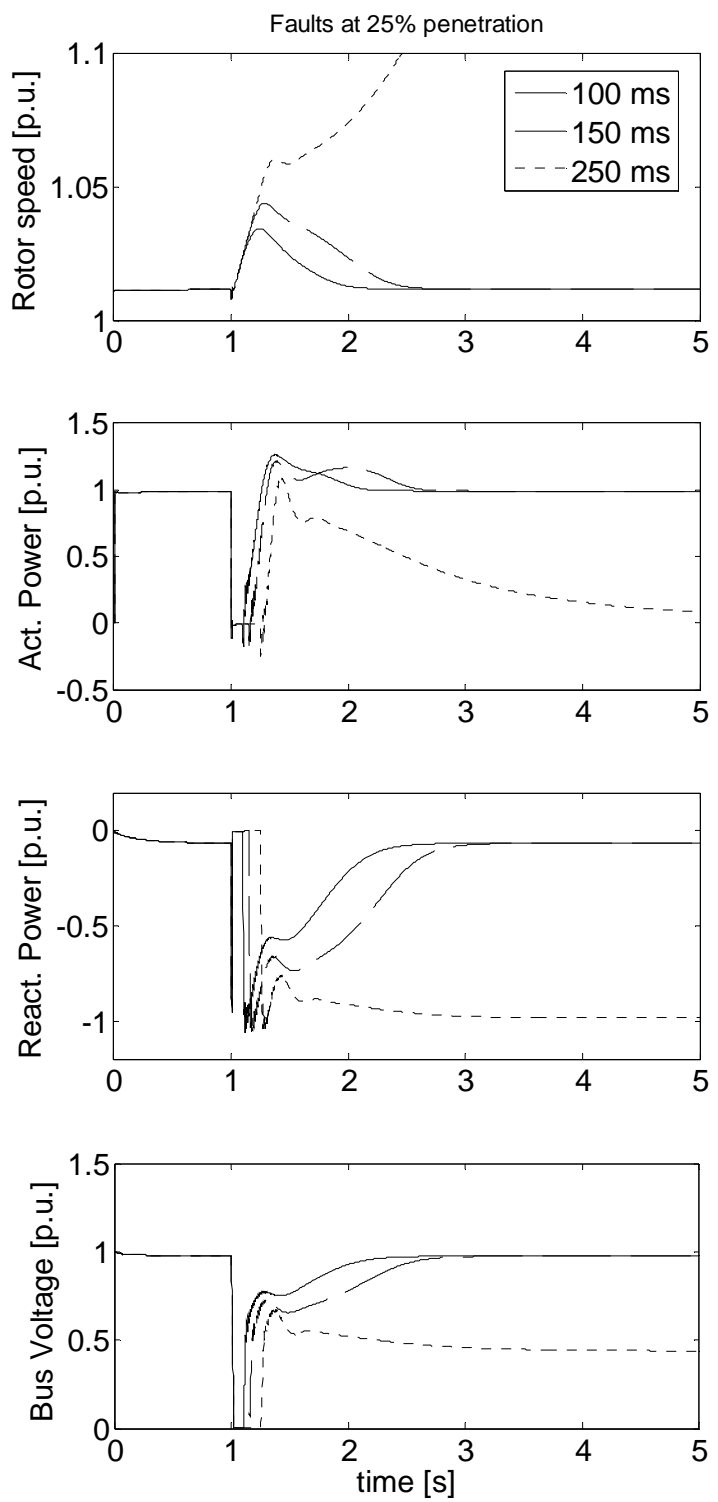

Fig. 3. Fault response of the reference system at $25 \%$ RPL with fault clearing times of 100,150 and $250 \mathrm{~ms}$.

\section{Simulation results}

\section{A. Transient stability tests}

The reference system and the system with DC-link were tested under the following transient perturbation events:

1. Mechanical torque pulse

2. 3-phase fault

3. Voltage dip

The impact on voltage and load flow stability during the perturbation events is investigated. Stability limits are identified by the variation of the grid strength.

\section{A.1. Fault response}

A three phase fault at the PPC was simulated. According to [1] three different fault clearing times were considered: $100 \mathrm{~ms}, 150 \mathrm{~ms}$ and $250 \mathrm{~ms}$.
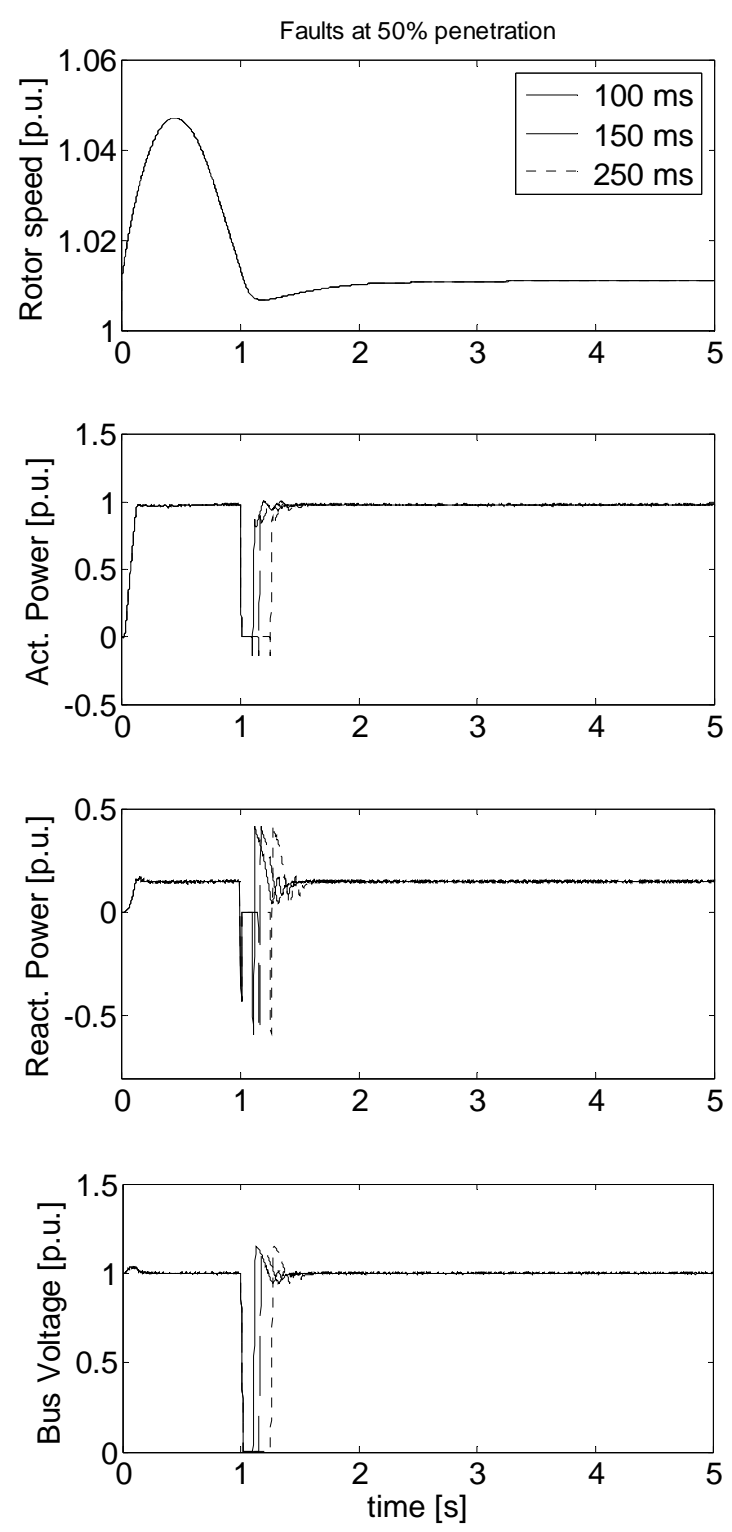

Fig. 4. Fault response of system with DC-link at $50 \%$ RPL with fault clearing times of 100,150 and $250 \mathrm{~ms}$. 
The reference system was tested for a number of renewable penetration levels (RPL) to find out the critical and unstable configurations. A summary of the results is given in TABLE III.

TABLE III. - Stability of the reference system depending on fault clearing time and RPL.

\begin{tabular}{ccc}
\hline $\begin{array}{c}\text { Fault clearing time } \\
\text { [ms] }\end{array}$ & critical RPL & unstable RPL \\
\hline 100 & $30 \%$ & $35 \%$ \\
150 & $25 \%$ & $30 \%$ \\
250 & $20 \%$ & $25 \%$ \\
\hline
\end{tabular}

Simulation results for the system with DC-link in voltage control mode at a RPL of $50 \%$ have been done. As expected, no instability problems occurred in this configuration because the inverter disconnects the generator from the grid during the fault while the generated energy is stored in the battery. When the voltage recovers, the inverter reconnects.
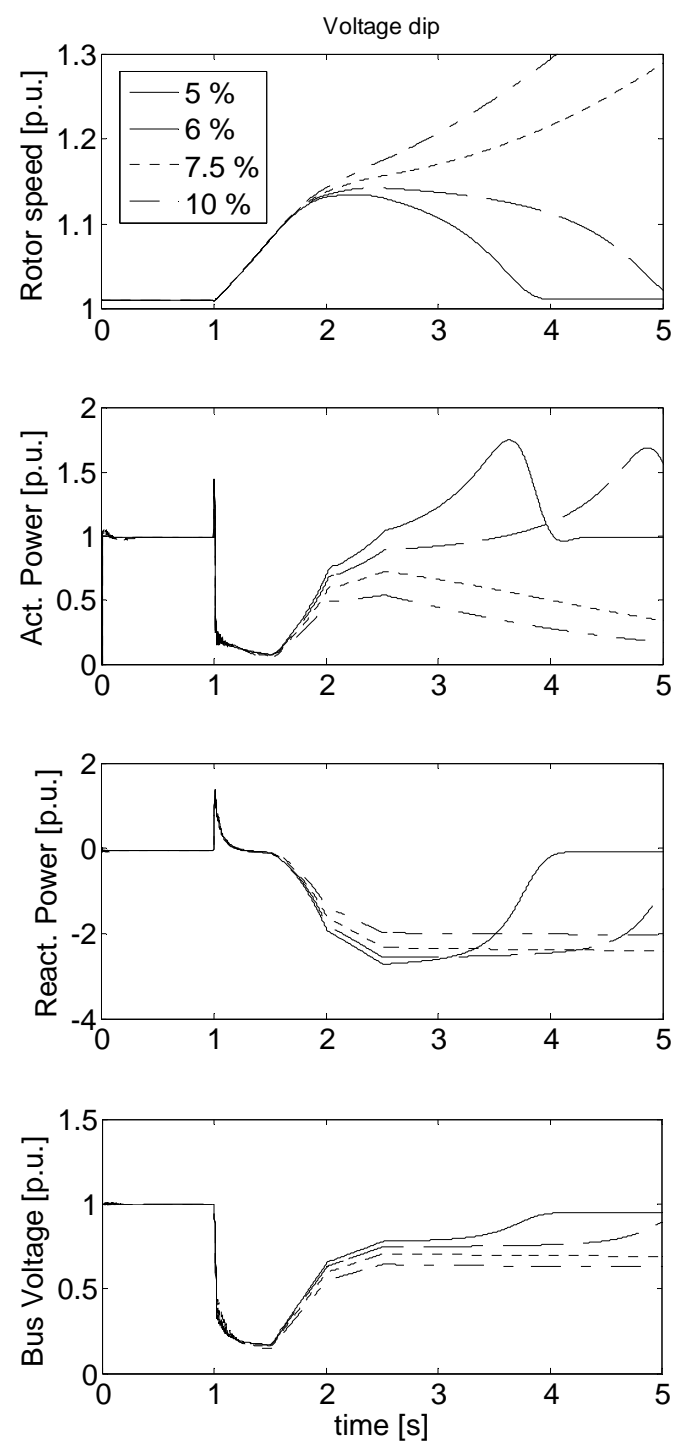

Fig. 5. Response of the reference system to a voltage dip with RPL at $5,6,7.5$ and $10 \%$.

\section{A.2. Voltage dip response}

The voltage dip was simulated according to the Spanish legislation draft [7]. The corresponding voltage-time curve is shown in Fig. 6.

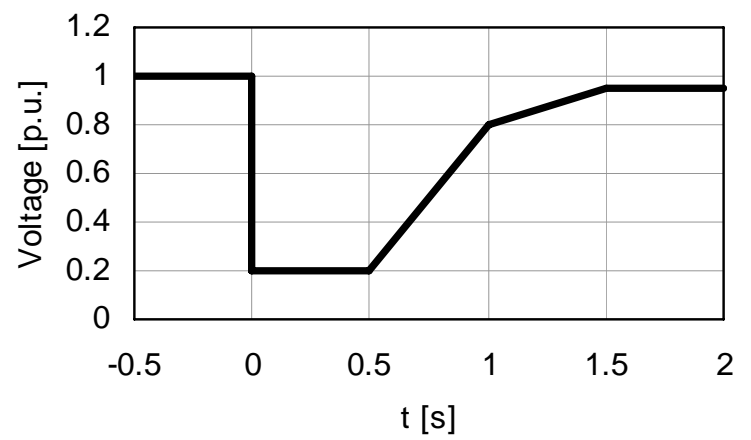

Fig. 6. Admittable voltage-time curve at the point of common coupling according to [7].
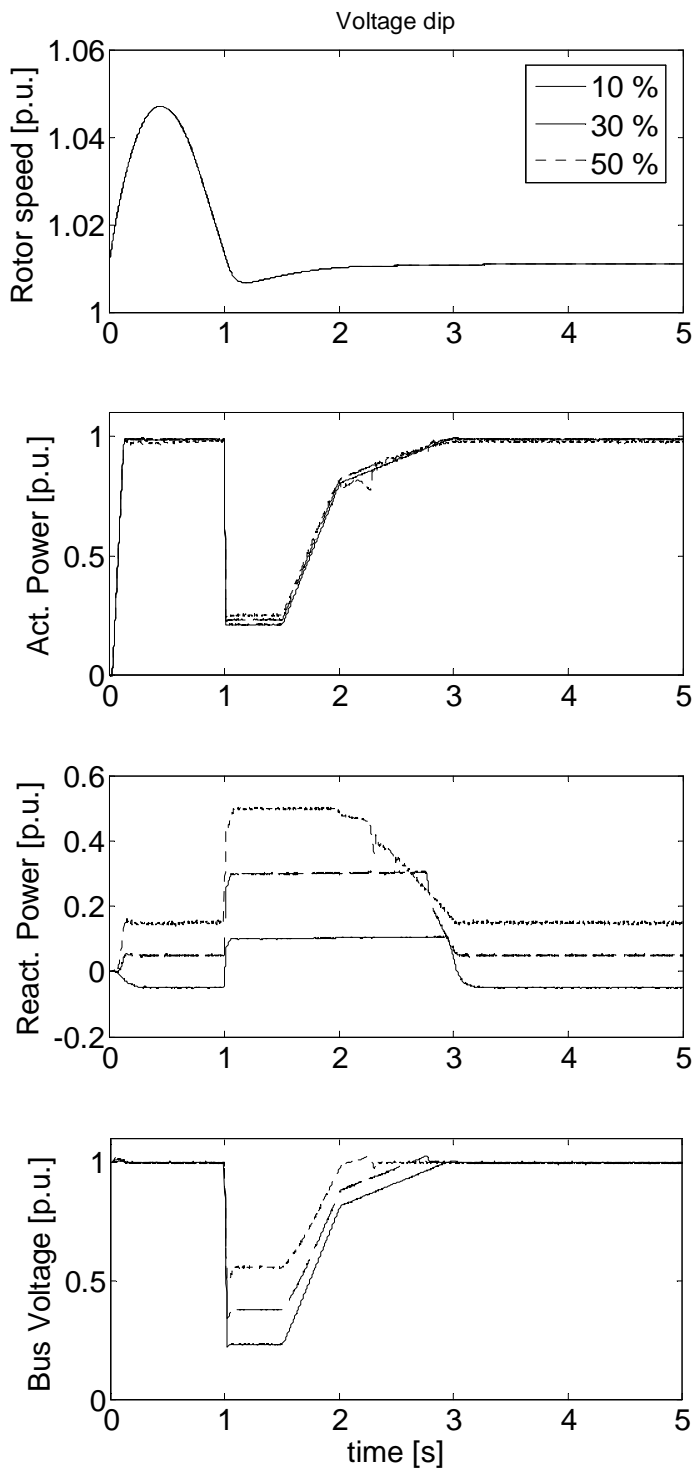

Fig. 7. Response of the system with DC-link (in voltage control mode) to a voltage dip with RPL at 10,30 and $50 \%$. 
The response of the reference system to the voltage dip is shown in Fig. 5. The range of grid strength had to be changed considerably in comparison with the short circuit stability simulations in order to get at least one stable result.

The voltage dip was found as the most severe of all simulated events. In reference [7] "Red Eléctrica Española" (REE) establishes a general maximum RPL of $5 \%$ for wind energy generation. Simulation results show good accordance with this limit as the reference system withstands the voltage dip and recovers within $3 \mathrm{~s}$ at a RPL of $5 \%$.

The response to a voltage dip of the system with DC-link is shown in Fig. 7. In "PF unity" control mode the system became critical at $20 \%$ RPL and was unstable at 30\%. Therefore only the configuration with voltage control is presented. The range of RPL was changed in comparison with the reference case in order to demonstrate the capability of the voltage control to maintain the system stable even for a penetration level of $50 \%$.
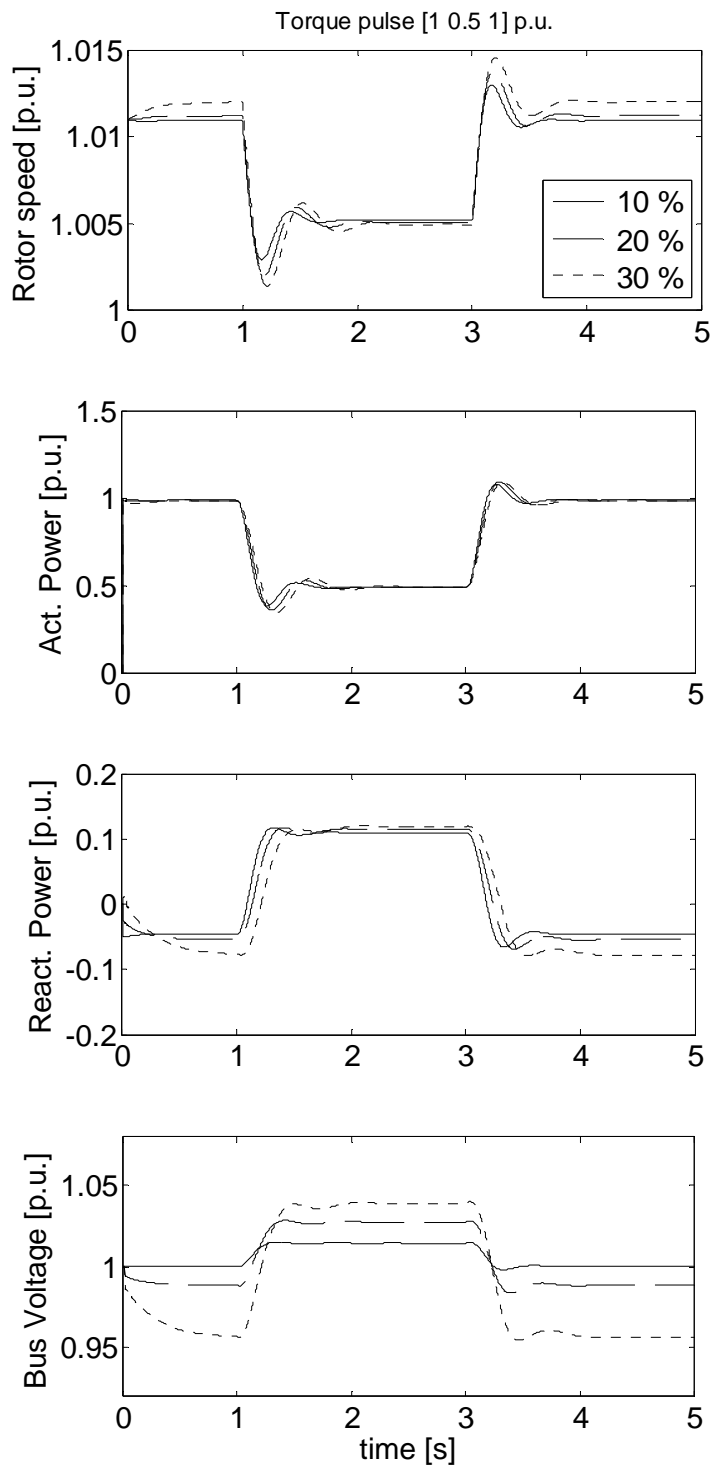

Fig. 8. Torque pulse response of the reference system with RPL at 10,20 and $30 \%$.

\section{A.3. Torque pulse response}

To simulate sharp changes in renewable energy generation (e.g. wind speed drops) a torque pulse was applied to the ASM generator. The pulse starts at $100 \%$ of nominal torque and falls after $1 \mathrm{~s}$ within $1 \mathrm{~ms}$ down to $50 \%$. After another second torque recovers to $100 \%$ within $1 \mathrm{~ms}$. This torque pattern permits to study two different events in one simulation run: a step up and a step down of the mechanical torque.

In Fig. 8 the response of the reference system is shown. Only the penetration levels which had been identified as stable were considered.
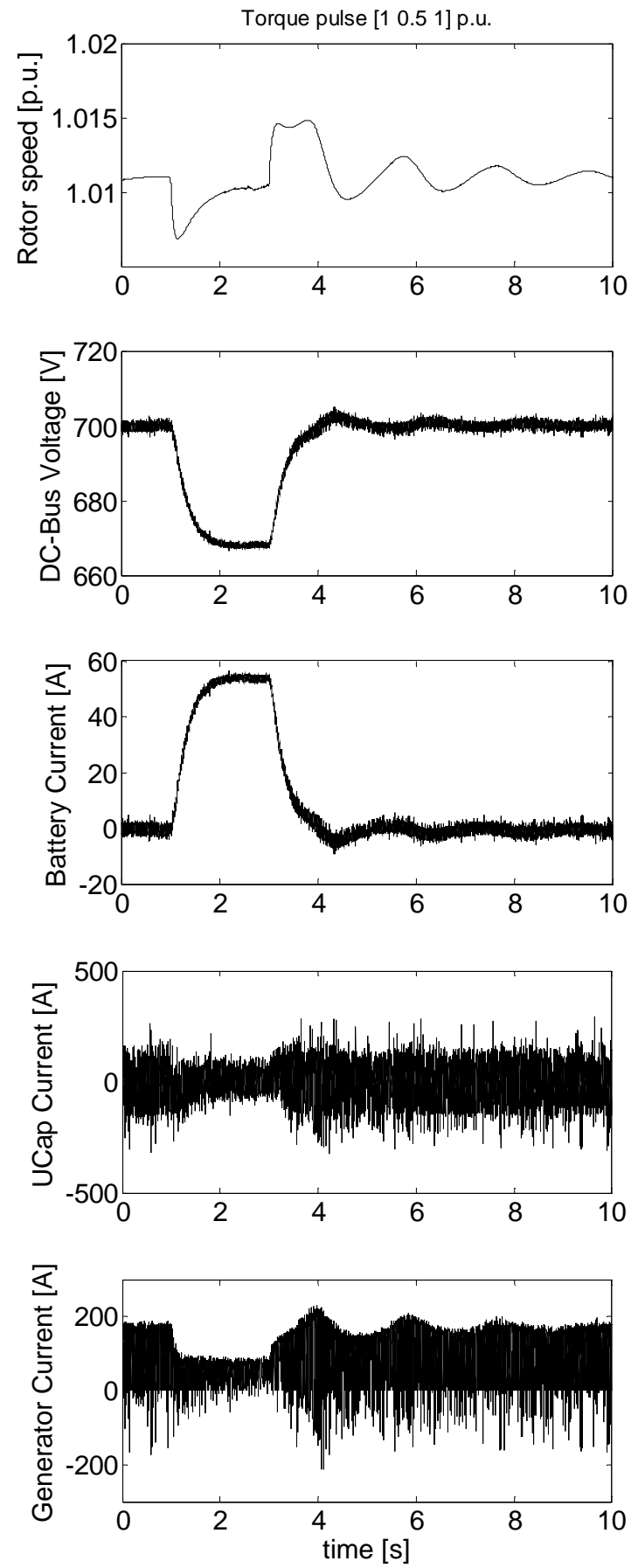

Fig. 9. Torque pulse response of the energy storage system at 50 $\%$ RPL. 
The torque pulse causes some oscillations but it has no mayor effect on system stability. One reason is that at a lower active power generation the reactive consumption of the ASM is reduced to. Because the compensation capacitor bank is not switched to a lower capacity in this case, during reduced power generation excess reactive power is fed into the grid and causes a voltage rise. On the other hand no loads are considered though the reduction of generation has no negative consequences. In a real EPS, a total generation loss of $15 \%$ could have serious consequences.

In the system with DC-link the battery acts as a spinning reserve and fully compensates the loss of generation. Therefore the output remains constant during the simulation interval. The battery modelled in this example was designed to level out generation fluctuations in 15 min time intervals (see [2]). Therefore a generation drop of $50 \%$ during $1 \mathrm{~s}$ obviously should not pose a problem to the energy storage system (ESS). The response of the ESS at the DC-link is shown in Fig. 9. The positive battery current indicates the discharge to compensate the generation loss.

It has to be mentioned that for RPL $50 \%$ the voltage distortion was already very high before the voltage dip. During the perturbation the situation is even worse. Although the stability could be maintained by reactive power injection, the DC-link introduced a very highly distorted voltage. New control and filter techniques are under development which in the future will overcome this problem.

\section{Harmonic distortion}

The noise that can be observed in the bus voltage and power curves indicates a basic problem of power injection to weak grid using IGBT - PWM technology. While the current ripple can be filtered quite easily by series inductivities at the inverter outlet, voltage deformations remain high. In the simulated case, even at a penetration level of only $10 \%$ the total harmonic distortion (THD) of the voltage at the injection point (PCC) reached about $8 \%$. In a practical application this would not be acceptable. Therefore in the future development of this approach special attention has to be paid to this issue. In order to limit the scope of the present work, no optimized filters were developed. At the inverter outlet only a $4 \mathrm{mH}$ inductivity is placed.

The worst case for the harmonic distortion problem is created by a voltage dip. In Fig. 10 the voltage trace during 4 cycles and its harmonic spectrum are shown. This picture was taken during a voltage dip with RPL 50 $\%$ and voltage control mode. Due to the voltage control, the fundamental amplitude of the voltage only fell to about $56 \%$. But the total harmonic distortion (THD) rose from $15 \%$ before the voltage dip up to $42 \%$. It should be mentioned that current THD is affected far less by the perturbation. During the voltage dip THD was at $1.3 \%$ while before it was around $1.15 \%$.
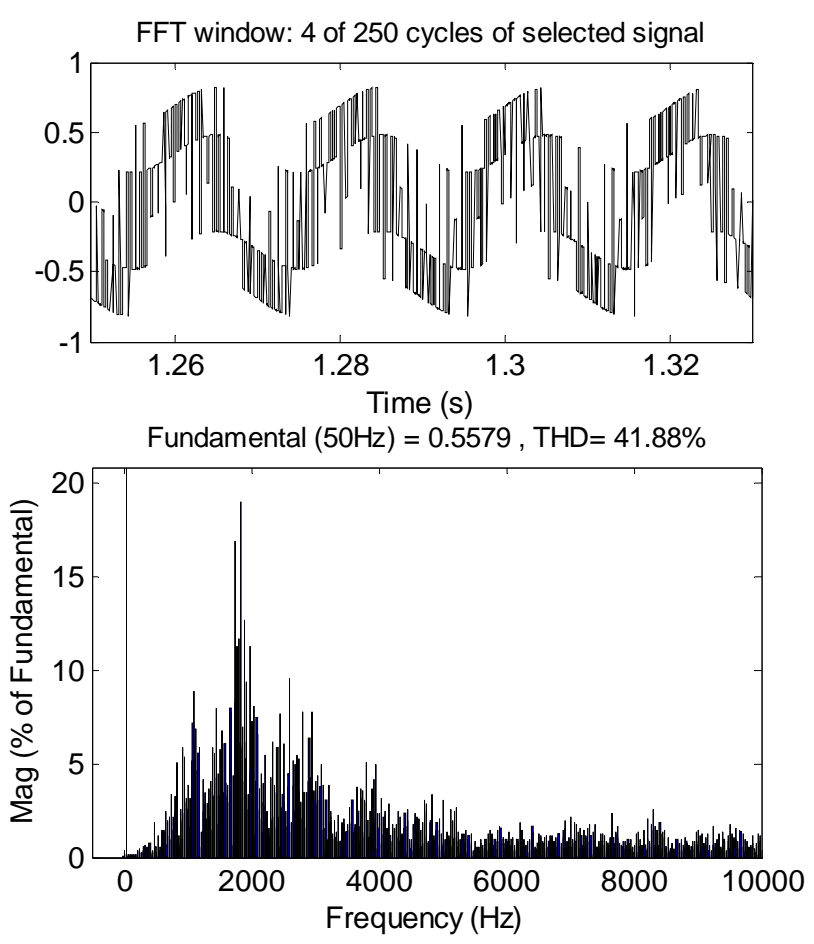

Fig. 10. Harmonic distortion of the voltage at the PCC during the voltage dip with voltage control and RPL at $50 \%$.

The inverter control strategy implemented in the simulation model is of the current hysteresis type. One important property of this control consists in the wide range of its frequency spectrum. Although the hysteresis band width defines roughly the mayor frequency, it produces frequencies of important amplitude which are over 10 times higher than this frequency peak.

In the presented simulations, a hysteresis band of $\pm 5 \%$ was chosen. This resulted in a frequency peak at around 2 $\mathrm{kHz}$. But to obtain the full frequency spectrum, the FFTwindow must include at least $25 \mathrm{kHz}$. For the IGBT switches this undefined switching frequency would cause problems in real applications. Therefore, a frequency limitation has to be included in the hysteresis control.

\section{Conclusion}

The impact of a squirrel cage induction generator (ASM) directly coupled to a distribution network was simulated with SIMULINK ${ }^{\circledR}$. Results were compared with simulations with a DC-link and energy storage (batteries and ultracapacitors) between generator and grid. Both configurations were tested with 2 types of disturbances: Voltage dip and 3-phase fault. The voltage dip was identified as the most critical event. Directly connected ASM generators are able to ride trough a voltage dip only if its nominal power is less than $5 \%$ of the short circuit power of the grid at the connection point. The DC-link with energy storage guarantees a stable power generation up to a renewable penetration level RPL of $50 \%$ if active voltage control is implemented. Severe harmonic voltage distortion was observed. The main contributions of this simulation model are the possibility of design and sizing of the storage system and new control and filter techniques to overcome the distortion problem. 


\section{References}

[1] J.G. Slootweg, "Wind Power - Modelling and Impact on Power System Dynamics", PhD Tesis, Technical University of Delft, 2003.

[2] H. Bludszuweit et. al, "Simulation of a hybrid system Wind Turbine - Battery - Ultracapacitor", International Conference on Renewable Energy and Power Quality ICREPQ’05, 2005.

[3] P.G. Pligoropoulos, E.K. Bakis, A. Engler, M. Vandenbergh, P. Strauss, "Wind diesel battery systems for the Greek islands Sifnos, Serifos and Astipalea", 2nd European PV-Hybrid and Mini-Grid Conference, 2003.
[4] N. Duic, L.M. Alves, M $\mathrm{M}^{\mathrm{a}}$ da Graça Carvalho "Optimising the integration of hydrogen usage with intermittent energy sources", Instituto Superior Técnico, Lisbon, Portugal, 2002

[5] "El Hierro - $100 \%$ Renewable Energy Island" http://www.insula.org/elhierro100.htm (last visited on january 27th 2006),

[6] P. Kundur, "Power System Stability and Control", ISBN: 0-07-035958-X, 1994

[7] P.O.12.3. "Requisitos de respuesta frente a huecos de tensión de las instalaciones de producción de régimen especial", preliminary operational procedure proposed by "Red Eléctrica Española" to be incorporated in the fourth additinal disposal of the Royal Decree 436/2004. 